\title{
DADOS CRONOLÓGICOS RELATIVOS À ARQUEOLOGIA DO OESTE DE MATO GROSSO
}

\author{
Ações de arqueologia preventiva realizadas \\ no oeste do Estado de Mato Grosso, no âmbito \\ dos projetos Salvamento arqueológico na área \\ impactada pelo gasoduto Bolívia-Mato Grosso/ \\ trecho brasileiro (portaria IPHAN n ${ }^{\circ} 11$ 04/03/ \\ 99, D.O.U. 05/03/99; contrato FAPEC/Gasocidente \\ do Mato Grosso Ltda.) - código 4 (ver tabela a \\ seguir) e Salvamento arqueológico na área a \\ ser impactada pela Usina Hidrelétrica Salto das \\ Nuvens (portaria IPHAN n ${ }^{\circ} 61$ de 24/10/2000, \\ D.O.U. 25/10/2000; contrato FAPEC/Cimento \\ Portland Mato Grosso S/A) - código 5 (ver \\ tabela a seguir), resultaram em novos dados \\ relevantes para o conhecimento dos processos de \\ povoamento humano dessa região, no passado \\ pré-colonial.
}

\begin{abstract}
A cronologia apresentada na tabela a seguir refere-se a diferentes contextos, espaciais e culturais pretéritos, tais como áreas de garimpo colonial nas proximidades de Cuiabá (ver amostras 292 e 293-FATEC), assentamentos pré-coloniais no interior da Província Serrana, em Cáceres (por exemplo, amostras 234 e 229-FATEC), ou ainda sítios arqueológicos localizados nas proximidades dos tributários da margem direita do alto curso do rio Paraguai, entre os rios Jauru e Sepotuba (ver, por exemplo, amostras 578 e 388-FATEC).

As datações do material cerâmico, empregando-se o método da termoluminescência, foram realizadas no Laboratório de Vidros e Datação da Faculdade de Tecnologia de São Paulo (FATEC), sob a coordenação da Profa. Dra. Sonia H. Tatumi.
\end{abstract}

Gilson Rodolfo Martins* Emília Mariko Kashimoto** Sonia Hatsue Tatumi***

(*) Laboratório de Pesquisas Arqueológicas do Departamento de História do Campus de Aquidauana da UFMS (LPA/DHI/CPAQ/UFMS).

(**) Laboratório de Pesquisas Arqueológicas do Museu Dom Bosco/Universidade Católica Dom Bosco, Campo Grande-MS (LPA/MDB/UCDB).

(***) Laboratório de Vidros e Datações da Faculdade de Tecnologia de São Paulo (FATEC). 


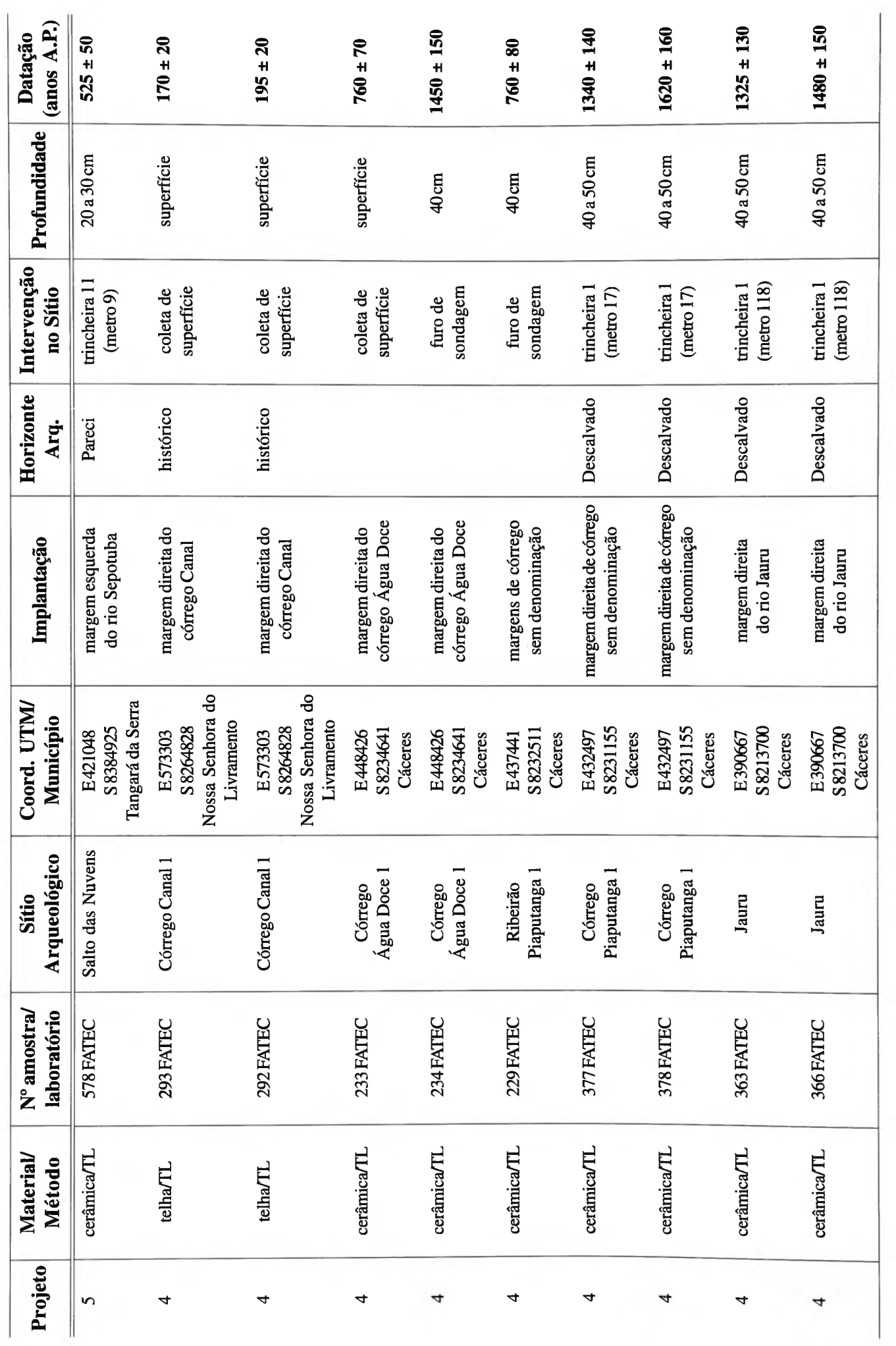




\begin{tabular}{|c|c|c|c|c|c|c|c|c|c|c|}
\hline 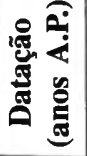 & 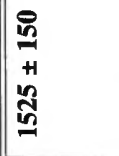 & $\begin{array}{l}R \\
+1 \\
0 \\
0\end{array}$ & $\begin{array}{l}\stackrel{0}{\circ} \\
+1 \\
\stackrel{\infty}{\infty}\end{array}$ & 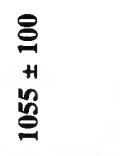 & $\begin{array}{l}\stackrel{O}{O} \\
+1 \\
0 \\
0 \\
0\end{array}$ & $\begin{array}{l}\text { త్ } \\
+1 \\
\text { త్ }\end{array}$ & 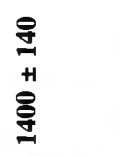 & $\begin{array}{l}\stackrel{\otimes}{=} \\
\stackrel{+}{+1} \\
\stackrel{0}{0}\end{array}$ & 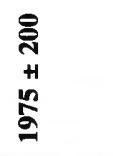 & 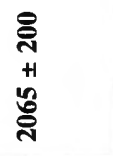 \\
\hline 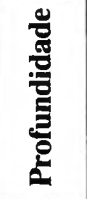 & 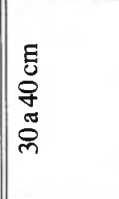 & $\begin{array}{l}\text { E } \\
8\end{array}$ & & E & $\begin{array}{l}\varepsilon \\
\delta \\
\delta\end{array}$ & हू & & हू & 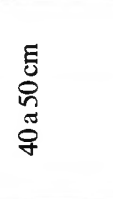 & $\begin{array}{l}E \\
0 \\
\mathscr{0} \\
\tilde{\sigma} \\
\sigma\end{array}$ \\
\hline 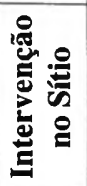 & 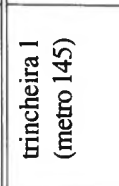 & $\begin{array}{l}\bar{\pi} \\
\overline{0} \\
\overline{0} \\
.\end{array}$ & 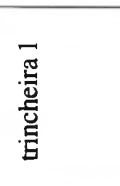 & 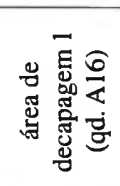 & 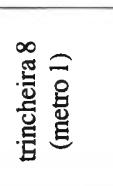 & 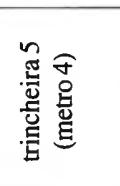 & $\begin{array}{l}\overline{\tilde{J}} \\
\overline{\tilde{g}} \\
\text { E }\end{array}$ & 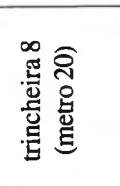 & 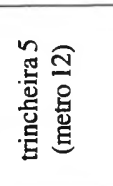 & 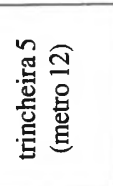 \\
\hline 这 & 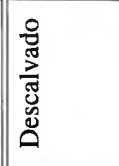 & 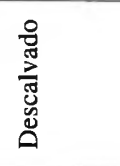 & 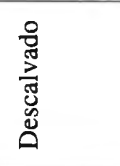 & 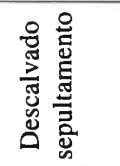 & & & 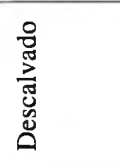 & & & \\
\hline 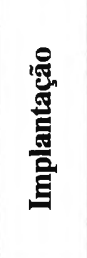 & 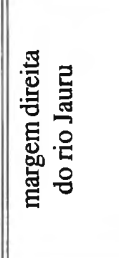 & 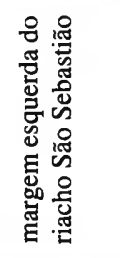 & 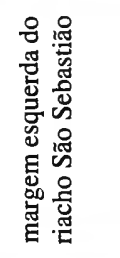 & 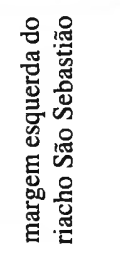 & 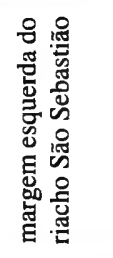 & 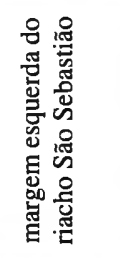 & 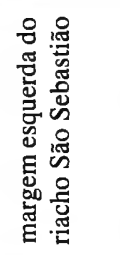 & 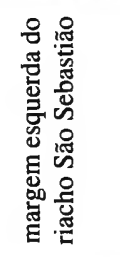 & 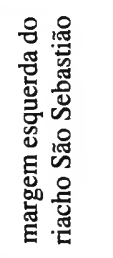 & 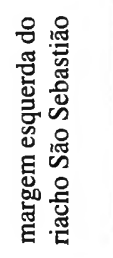 \\
\hline 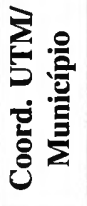 & 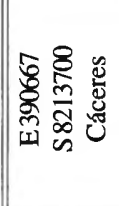 & 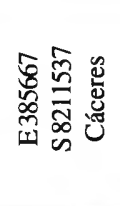 & 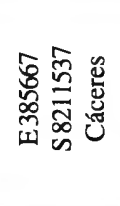 & 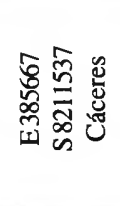 & 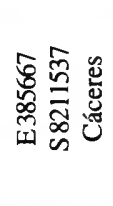 & 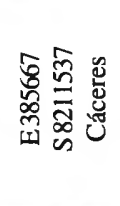 & 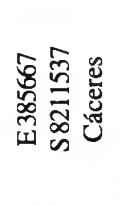 & 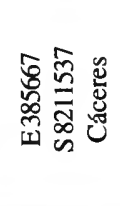 & 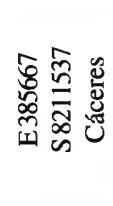 & 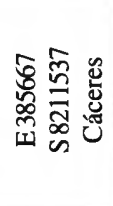 \\
\hline 㵧 & $\mid$ & 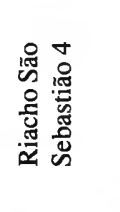 & 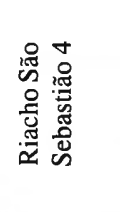 & 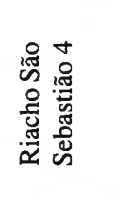 & 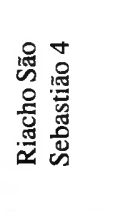 & 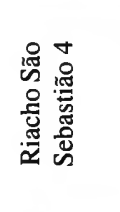 & 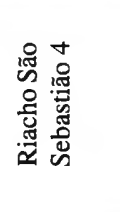 & 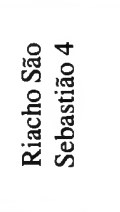 & 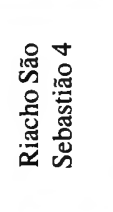 & 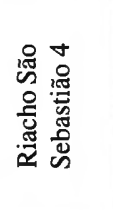 \\
\hline 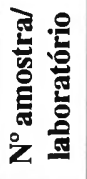 & 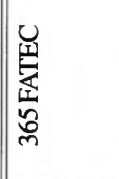 & 惫 & 芯 & 峁 & 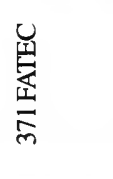 & 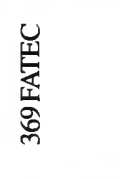 & 岕 & 总 & 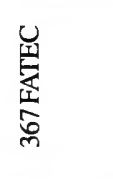 & 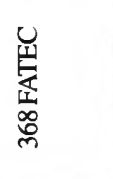 \\
\hline 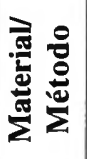 & 䲩 & 廌 & 㷇 & 麃 & 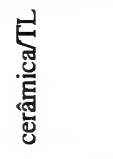 & 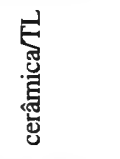 & 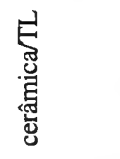 & 窇 & 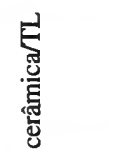 & 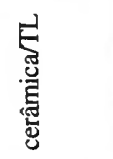 \\
\hline$\frac{8}{\frac{3}{3}}$ & $\sigma$ & $\nabla$ & + & 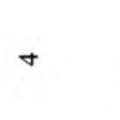 & $\nabla$ & $\nabla$ & $\nabla$ & $\nabla$ & $\nabla$ & $\forall$ \\
\hline
\end{tabular}




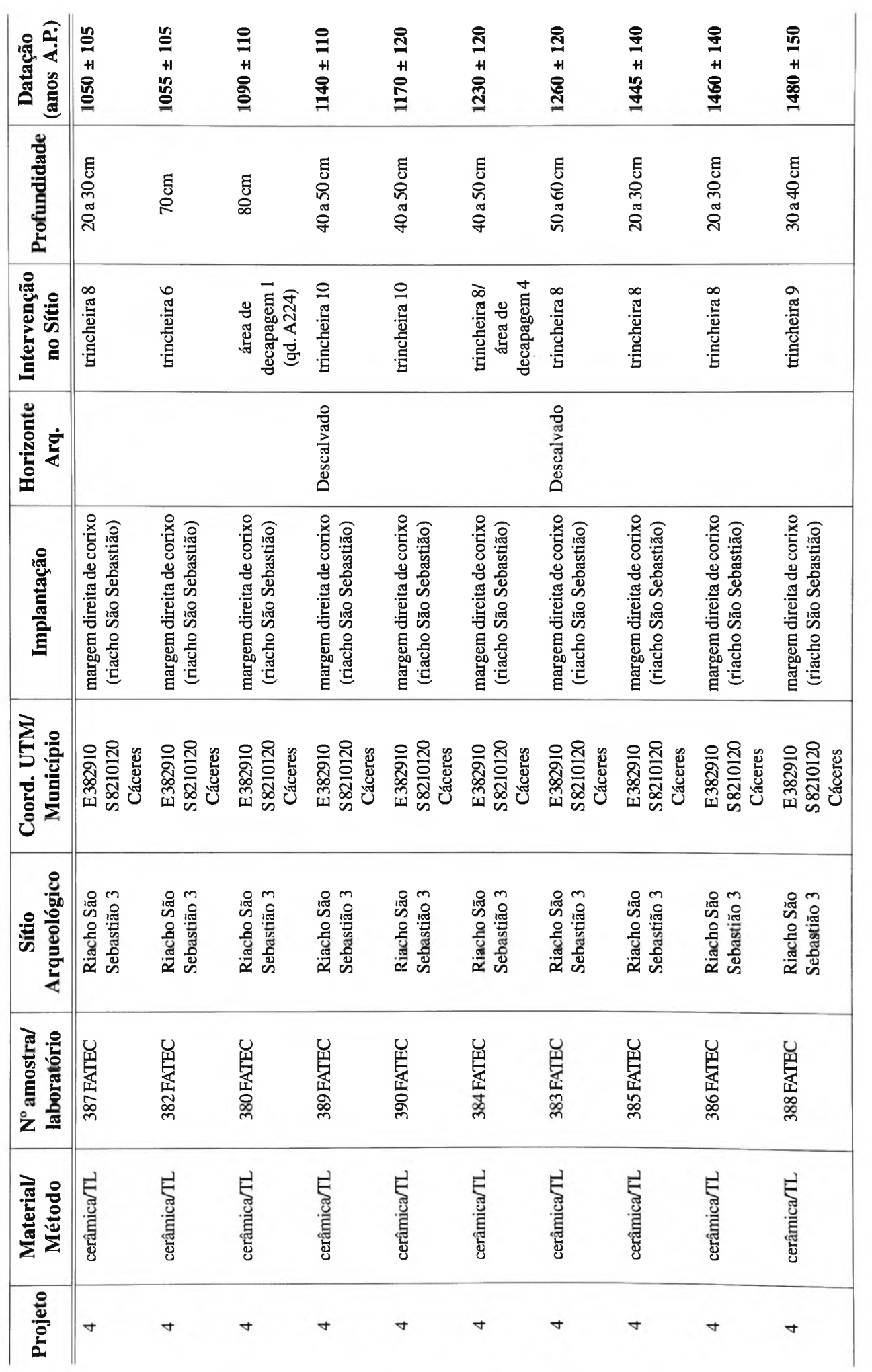

